\title{
No Tempo dos Loronhas se Erguia uma Ilha-Presídio no Atlântico
}

(1504-1800)

Grazielle Rodrigues do Nascimento

\begin{abstract}
RESUMO
Como disse Américo Vespúcio, em 1503: O Paraíso é aqui, referindo-se a ilha de Fernando de Noronha. Analisar a participação desta ilha como um espaço construtor de relações econômicas e sociais para a história do Brasil, nos remete ao inicio do povoamento português, cujo período das descobertas Lusa pelo Atlântico insere Fernão de Loronha, fidalgo da Casa Real Portuguesa, neste contexto. Diferentes são os relatos a respeito da ilha. Sinônimo de paraíso, o estigma de ilha do terror viria conforme a utilidade de Fernando de Noronha ao recebimento de gente presa, cujo período marca a estrutura erguida para acomodar quem estava a serviço da Ordem e quem estava condenado as duras penas. Portanto, neste trabalho, especificamente, procuramos abordar o período da passagem portuguesa pela ilha de Fernando de Noronha, que a utilizam como ponto estratégico a segurança da rota comercial entre a recém colônia portuguesa (a Terra de Santa Cruz) e a metrópole. Assim, a chamada Ilha-Presídio construiria o estigma de terror e expiação aqueles que se aventurava a povoá-la.
\end{abstract}

Palavras-chaves: Portugal, Fernão de Loronha, Ilha-Presídio.

\section{ABSTRACT}

As say Americo Vespúcio about Fernando de Noronha island: the Paradise is here. Analyze this island into Brazilian history as a space builder around economic and social relations, brings us to understand the beginning of Portuguese settlement specify the period of discoveries by Lusa Atlantic. Synonymous of the Paradise, the stigma of the island of terror would come as the usefulness of Fernando de Noronha prison. This period beginning the structure built to accommodate those who were in the service of the Order and who were sentenced to severe punishment. So in this paper, specifically, we want to understand the period of the Portuguese passage through the island of Fernando de Noronha, who uses it as a strategic security of the trade route between the Portuguese colony (Santa Cruz) and the metropolis. Thus, the islandprision build the stigma of terror and atonement those who venture to populate it.

Key-Words: Portugal, Fernão de Loronha, Island-Prision.

Porque a ilha não é apenas a beleza dos seus picos e a cor transparente do mar nos arrecifes.

É também o seu calçamento de pedras transportadas no lombo nu dos desterrados,

dispostas no chão à unha. ${ }^{1}$

Os estudos sobre ilhas na historia do Brasil ainda não é algo tão difundido pelos meios acadêmicos. Salvo alguns pesquisadores como Carlos Diegues, Jana da Rocha Lima, Rosane M. Prado, Anamaria Beck, entre outros, que se dedicaram as pesquisas antropológicas, para a historia este tema ainda se apresenta como um campo fértil de enunciados e objetos.

\footnotetext{
*É Mestre em História Social pela UFPE e colaboradora do Arquivo Público Jordão Emerenciano. Atualmente preside o Centro de Pesquisa Histórica e Cultural de Fernando de Noronha, coordenando o Grupo de pesquisa Noronha Multifacetado.

1 NILSON, Emerson. Poesia: Em Fernando de Noronha, 2006. imagem: Carta das Terras e dos Mares do Globo Terrestre - M. BONNE. Detalhe a ilha de Fernando de Noronha, 1782. acervo particular de Baccaro.
} 
Tomando como um dos objetivos dos estudos históricos a possibilidade de analises e construções de enunciados no entorno das relações construídas entre os seres humanos, os objetos que ele produz e a memória (ora lembrada, ora esquecida) é que a construção de narrativas históricas sobre a passagem e a participação humana em ilhas, seja para povoá-la, desenvolver o comercio marítimo e/ou utilizando-a como "deposito de gente", este ambiente insular nos proporciona muitas historias sobre a nossa passagem pela Terra, ora sendo narradores participativos ora sendo expectadores.

Como cita Peter Burke, em seu livro A Escrita da História,

os narradores históricos necessitam encontrar um modo de se tornarem visíveis em sua narrativa, não de auto-indulgência, mas advertindo o leitor de que eles não são oniscientes ou imparciais e que outras interpretações, além das suas, são possíveis. ${ }^{2}$

Neste sentido, a participação da ilha de Fernando de Noronha como um espaço construtor de relações sociais para a história do Brasil, é por nos tomada como campo de analises historiográfico ainda escasso diante a importância deste pedaço de terra brasileira no Atlântico. E que muitas vezes recorre em erros de análises reduzindo a participação desta ilha ao processo civilizador apenas como um "Paraíso de Natureza Intocável", cuja idéia de estratégia comercial e ponto de apoio ao povoamento das terras "recém conquistadas" por Portugal, estejam à margem das discussões históricas e fragmentando com a idéia de que a ilha foi o lócus dos primeiros trabalhos antropológicos em que concentrava num só espaço as fronteiras da idéia de sociedade, cultura e território. (DIEGUES 1998: pp 97).

A participação da ilha de Fernando de Noronha na construção do que iria ser Brasil, nos remete ao inicio do povoamento português, cujo período das descobertas Lusa pelo Atlântico insere um fidalgo da Casa Real Portuguesa em um cenário da história colonial.

\footnotetext{
2 BURKE: pp 337.
} 


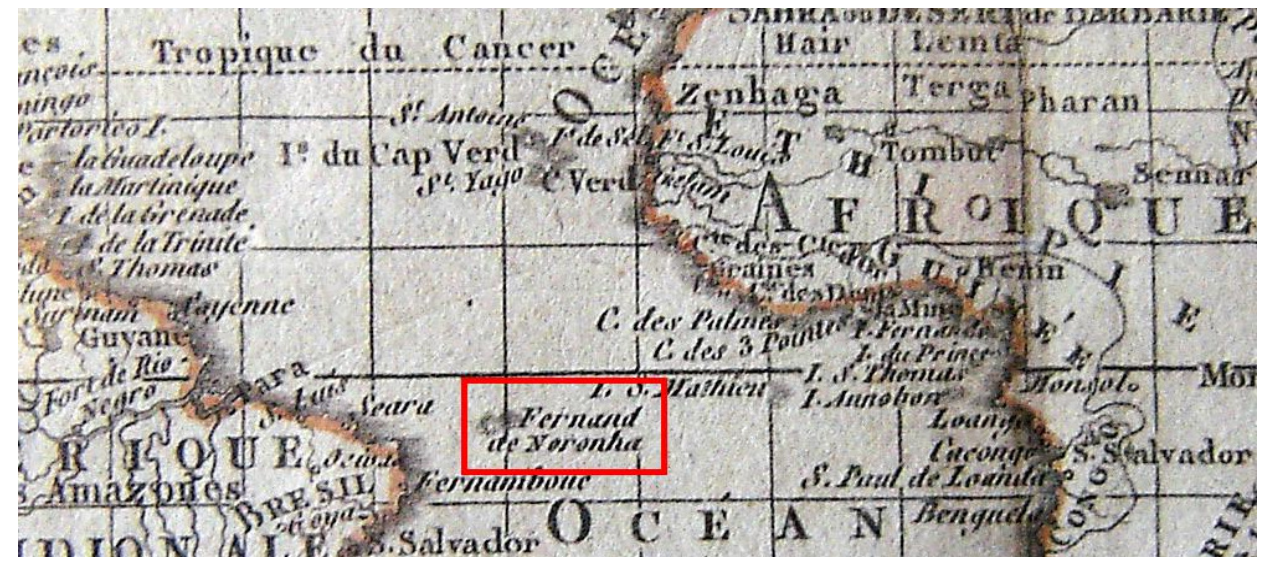

llustração 1 - Carta das Terras e dos Mares do Globo Terrestre - M. BONNE. Detalhe a ilha de Fernando de Noronha, 1782. Acervo particular de Baccaro.

A ilha de Fernando de Noronha, enquanto espaço sócio-cultural tem início quando o primeiro ser humano começava a trafegar pelo Atlântico. E, ai, não podemos relegar a segundo plano os diferentes relatos de marinheirosviajantes que mesmo sem ter aportado na llha, registraram-na em suas mais distintas formas de narrar o novo: em mapas (Juan de La Cosa 1500), em cartas náuticas, em relatos de viagens (Darwin - the voyage of the Beagle, 1832) ou até mesmo a descrevendo em detalhes como foi o caso de Américo Vespúcio em sua quarta viagem exploratória, em 1503, a mando do rei de Portugal D. Manuel IV, considerando-a uma "verdadeira maravilha da natureza" ${ }^{3}$.

[...] e quando tínhamos navegado bem trezentas léguas pelo mostro do mar [...] surgiu uma terra de que podíamos distar dela 22 léguas, da qual ficamos maravilhados e descobrimos ser uma ilha no meio do mar, e era coisa muito alta, de fantástica beleza natural, tendo não mais de duas léguas de comprimento e uma de largura. Esta ilha jamais foi habitada por qualquer população. (VESPÚCIO, 1504, apud FONTANA, 1994,1995, p. 178).

Há três versões sobre o que prefiro denominar de "achamento" da llha e que chegaram a atualidade de Noronha de maneira intrigante: uma se sobrepondo em mais detalhe (e diga-se de passagem, em mais "verdade") que a outra numa disputa de memória e do fato "verdadeiro". Qual data verdadeira ao descobrimento da ilha de Fernando de Noronha? Esse entendimento parte da enunciação de que os discursos construídos em torno de um efeito de verdade dado por uma concepção histórica factual sobre o momento preciso da

3 Quando da Quarta viagem (1503-1504) realizada. Informação encontrada no site: http://pt.wikilingue.com/ca/Amerigo_Vespucci. Acesso em 10 de janeiro de 2009. 
ilha-descoberta determina o funcionamento de diferentes práticas de poder como justificação racional para essa verdade, presente nos mecanismos estratégicos de poder e que geram seus efeitos. ${ }^{4} \mathrm{E}$ ao analisarmos esses efeitos de poder percebemos que a construção de uma história calcada no olhar do de fora marca o poder discursivo na construção da historia de Fernando de Noronha. Neste sentido, a utilização das fontes documentais, sejam elas tomadas como fonte escrita, fotográfica, mapas, discos, relatos orais, etc, nos conduzem a perceber o movimento da humanidade como uma trama que envolve diferentes categorias de analises, que interagem entre si e entre o ambiente que se inserem, reforçando a idéia de verdade.

Especificamente para o historiador, a utilização de documentos proporciona a percepção de diferentes relações sociais, relações de poder e de identidades. A ampliação do campo de investigação do conhecimento histórico constrói meios de democratizar o acesso a estes documentos permitindo a sistematização de novas fontes, de novos referenciais teóricos e de novas metodologias. Diante disto, até onde uma fonte pode ser tomada como verdadeira, ou até onde uma fonte revela a verdade absoluta de um determinado evento histórico? Perceber como o acesso ao passado é mediado por um discurso capaz de montar uma narrativa produtora de efeitos de verdade, cheia de significados que dão ou não veracidade a obra que construímos, requer construir uma narrativa que segue uma "operação historiográfica", como nos aconselha Roger Chartier. Citado isto, como analisar os efeitos de verdade engendrados pelo evento tomado como único sobre o descobrimento da ilha de Fernando de Noronha? Onde se aproximam e distanciam as versões sobre este evento?

A primeira versão é de responsabilidade do historiador português chamado Duarte Leite Pereira. Esse tomando como base os registros de uma expedição não oficial ocorrida provavelmente entre os anos de 1502-1503, defende a hipótese de que o próprio Fernão de Loronha iniciou a exploração dessas terras por ele batizada de São João da Quaresma, arrendando-a em

\footnotetext{
${ }^{4}$ Cesar Candiotto ressalta em artigo para a Revista de Filosofia da Unesp (2006), a analise critica elaborada por Foucault ao longo de sua reflexão sobre a verdade e os seus efeitos de poder. Professor de filosofia da PUC do Paraná, Cesar trata dos aspectos do saber, do poder, da ética e dos governos trazendo Foucault à discussão sobre a crítica da verdade. pp 69-70.
} 
contrapartida a exploração de pau-brasil. Esta informação é encontrada no Plano de Manejo de $2004^{5}$ e pouco difundida na ilha.

A segunda versão para o achamento versa que depois de oficializada a posse das terras do Além-Mar, em 1500, Pedro Álvares Cabral decidiu enviar uma de suas naus a Portugal com a notícia da posse dos novos territórios denominada Terra de Santa Cruz. Entregou a responsabilidade da missão a Gaspar de Lemos, responsável pelas provisões da frota. Esse levaria a cartanotícia escrita pelo escrivão oficial da expedição que era o Pero Vaz de Caminha. Após receber as instruções de que costearia o norte das terras recém conquistadas, Lemos partiu em 02 de maio de 1500, e depois de percorrer durante 53 dias de viagem a costa norte, avistou uma ilha que a denominaria de Ilha de São João. Isto, talvez, explique o motivo do rei de Portugal D. Manuel I ter posto na carta de doação a Fernão de Loronha a posse à ilha de São João ${ }^{6}$.

A terceira versão é a costumeiramente mais difundida na ilha atualmente. Trata-se que em 1503, foi enviada a quarta expedição de caráter exploratória a Terra de Santa-Cruz, tendo como um dos comandantes da frota de Gonçalo Coelho, Américo Vespúcio, e patrocinada por um consórcio de cristãos-novos associados a Fernão de Loronha. Perdendo-se do resto da armada, carregou o navio de pau-brasil ao sul da Baía de Todos os Santos, desembarcando em Lisboa no dia 18 de junho de 1504. Afirmou então haver estado em um novo mundo, ao qual dera o nome de São Lourenço (Costa: 1887).

Portanto, ao ler as notícias a respeito da data e do "descobridor" da Ilha de Fernando de Noronha percebemos uma disputa de memória para a data inicial da história de Fernando de Noronha, como se houvesse um determinismo para essa história. Este confronto de datas permite-nos observar que o olhar do estrangeiro legitima a construção de uma história recém descoberta pela historiografia e que precisa ser revisitada. $O$ que devemos destacar não é a data precisa do "descobrimento" tão pouco o registrodocumento que narra a verdadeira data, precisa, do momento exato que a ilha fora "descoberta", mas compreender como os discursos foram sendo 
construídos para que Américo Vespúcio fosse tomado, e legitimado, como o grande nome desse feito. Por que Vespúcio recebeu a alcunha de descobridor dessas terras portuguesa, onde coube ao Fernão de Loronha a sua posse? 0 que de relevante há na construção de um fato histórico como algo de grandioso e/ou único? Mesmo porque ambas as expedições do período entre 1501 e 1503, tinham a participação do Fernão de Loronha. Adicione a isso também outros referenciais de documentos capazes de proporcionar analises sobre território e estratégia, como por exemplo, o mapa de Juan de La Cosa e o mapa de Alberto Cantino que retratam a ilha nos anos de 1500 e 1503, respectivamente, caso houvesse a necessidade de entrarmos na discussão sobre qual a fonte documental capaz de legitimar o fato verdadeiro em torno desta descoberta, numa visão marcadamente positivista do século XIX.

Por outro lado, não há consenso entre os autores que tratam deste momento da historia insular fernandina, como Pereira da Costa (1887), Beatriz Imbiriba (1946), o próprio Duarte Leite (1945) citado anteriormente, Hélio Vianna (1961), Lisias Rodrigues (1943), entre outros. ${ }^{7}$

Contudo, o que aproximam esses autores na construção de suas narrativas acerca da historia da ilha de Fernando de Noronha é o fato desta ilha ter sido a primeira Capitania Hereditária do Brasil trinta e quatro anos antes de ser implantado o sistema de Capitanias pela metrópole portuguesa. Em 16 de janeiro de 1504, D. Manoel I, El Rei de Portugal através de uma Carta Regia, concedia a Fernão de Loronha aquele "pedaço de paraíso",

cujo direito caberia a todo tempo em que fosse povoada... mercê esta que por seu falecimento passaria a um de seus filhos... para nela lançar gados e a romper e aproveitar segundo mais the aprouvesse (Costa 1887: 19-20).

\footnotetext{
7 Sobre a história da ilha de Fernando de Noronha entre os séculos XV e XIX ver: Beatriz de Lalor Imbiriba História de Fernando de Noronha. Imprensa Industrial. Recife, 1951; Guilherme Auler Os Fortes de Fernando de Noronha. In: Revista do Arquivo Público. $2^{\circ}$ semestre, Recife, 1946; Lisias Rodrigues Fernando de Noronha. In: Revista do Instituto Arqueológico, histórico e geográfico de Pernambuco. Vol. XXXVIII. Pernambuco, 1943; Duarte Leite Quem Descobriu a llha de Fernando de Noronha. IN: Revista do Instituto Arqueológico, histórico e geográfico de Pernambuco Vol. XL. Pernambuco, 1945; Mário Melo O Arquipélago de Fernando de Noronha. IN: Revista do Instituto Arqueológico, histórico e geográfico de Pernambuco Vol. XVIII. Imprensa Industrial. Pernambuco, 1919; Francisco Pereira da Costa A ilha de Fernando de Noronha. Pernambuco, 1887; Orlando Machado; Joaquim de Souza Leão; Campos de Aragão Guardando o Céu nos Trópicos. Rio de Janeiro: Biblioteca do Exército, volume 147, 1950; Amorim Neto Fernando de Noronha. Editora A Noite. $2^{a}$ edição - Rio de Janeiro, 1946. Sem contar os relatórios militares que narram parte da história da llha de Fernando de Noronha.
} 
A partir de então, a saga dos Loronhas se entrecruzava com a historia da ilha de isolamento, esquecimento, cárcere e de prisão ao logo dos séculos de passagem humana pelas águas do Oceano Atlântico. Segundo os autores que tratam deste período, durante os anos em que Fernão de Loronha tivera com a posse do conjunto de ilhas, denominada de São João, não desenvolveu economia tampouco população, ficando este novo território exposto a outras nações que se encontravam em busca de novas terras e riquezas.

\section{A llha sob a Posse dos Loronha's:}

O mar é belo e terrível.

O mar é livre, dizem, e livre são os que vivem nele. ${ }^{8}$

A vida na llha dos Loronha's começava a ser traçada a partir das relações mercantis que se apresentavam no mundo moderno. Não era a toa que por muitas e muitas vezes lançaram-se ao mar homens com destinos a mundos desconhecidos, mas com um único objetivo: a busca por ouro, prata e pedras preciosas. Esses objetos cobiçados eram determinantes aos cofres das nações européias, detentoras do capital naquela época. Essa imagem não se encontrava apartada do cotidiano de Fernão de Loronha, que para garantir o monopólio comercial com o novo mundo recém-conquistado, no caso a Terra de Santa Cruz, acabara aceitando a posse de uma terra sem ligação cultural ou de herança com ele. Há quem afirme, inclusive, que Fernão de Loronha nunca tenha aportado pelos mares da ilha que levaria o seu nome séculos mais tarde e, reconhecidamente na atualidade, como a ilha de Fernando de Noronha. $O$ historiador Hélio Vianna destaca que esta doação tinha suas origens no arrendamento da extração do pau Brasil

\footnotetext{
a mercadores de Lisboa, que também se comprometeram a explorar (...) Um dos arrematantes do contrato, o rico cristão-novo Fernão de Loronha, preparou a frota que sob seu comando, ou de outrem, por sua conta, ou com a associação de outros mercadores, veio ao Brasil em 1503 (...) o que positivamente sabemos é que em conseqüência dessa viagem, a 16 de janeiro de 1504 doou D. Manuel I a Fernão de Loronha a ilha de São João... foi essa aliás a primeira capitania hereditária do Brasil, que logo tomou o nome de seu donatário. ${ }^{9}$
}

\footnotetext{
${ }^{8}$ AMADO, Jorge. Mar Morto. $79^{\circ}$. ed. Rio de Janeiro: Record, 2001. pp 46.

9 Vianna: pp 52.
} 
Rico empreendedor, comerciante e armador, natural das Asturias, Loronha era representante do banqueiro alemão Jakob Fugger na Peninsula Iberica e juntamente com outros cristãos-novos, comerciantes portugueses, obteve concessão para explorar os recursos naturais do Brasil por mais de dez anos. O consórcio financiou a expedição de Gonçalo Coelho no mesmo ano de 1503.

Em 1506, Loronha e os sócios extraíram das novas terras mais de 20 mil quintais de pau-brasil, vendidos em Lisboa com um lucro de $400 \%$ a $500 \%$. Em um documento da Torre do Tombo (Portugal), o rei português D. Manoel I (da dinasia de Avis-Beja) emitiu Alvará exigindo que Tomé Lopes pagasse a Fernão de Loronha "cento e tantos quintais do Brasil"10 que tinham vindo na nau Santa Maria do Campo. Em 1511, associado a Bartolomeu Marchioni, Benedito Morelli e Francisco Martins, participou da armação da nau Bretoa, que a 22 de julho retornou a Portugal com uma carga de 5.000 (cinco mil) toras de pau-brasil, animais exóticos e 40 escravos, mulheres em sua maioria.

Com o fato consumado em torno da posse da ilha de São João, em plena região sul do Oceano Atlântico, se constituía a primeira Capitania (do mar) fora de águas portuguesas. Pena não ter havido interesse por parte de Fernão e seus herdeiros em desenvolvê-la a exemplo do que acontecera com Açores, Cabo Verde e Madeira. A ilha permaneceu sob a posse dos Loronha's até 1700, quando D. Pedro II, em Carta Régia de 24 de setembro, determinou a sua anexação a capitania de Pernambuco dada a sua proximidade geográfica, o que permitiria mais facilmente realizar os projetos de povoação e fortificações em Fernando de Noronha. (AULER: 1946, pp 37.)

Fidalgo português de descendência britânica, Fernão de Loronha converteu-se ao cristianismo provavelmente para escapar da inquisição. Contudo, não há voz unanime sobre este tema. Historiadores contemporâneos, como Lúcio de Azevedo, Duarte Leite, Jaime Cortesão e António Balão não se arriscam com tal afirmativa. Nem o fato do Fernão de Loronha ter presidido a uma associação de judeus conversos, nem as mercês régias que o cumularam ou a sepultura cristã de seu pai, são razões decisivas para confirmar ou infirmar a idéia de que o Fernão de Loronha era judeu. Por outro lado, Fernão

\footnotetext{
10 Arquivo do Tombo, Portugal. 1514-01-20. Corpo Cronológico, Parte I, mç. 116, nº 8.
} 
de Loronha se firmara como um grande armador e liderou o consórcio de exploração do pau Brasil nas novas terras portuguesas, supostamente, até os anos de 1540, mediante tributos à coroa e comprometimentos no envio de seis navios por ano para tal fim. ${ }^{11}$

Os registros até então encontrados a respeito dessa família cujo brasão foi conseguido, em 26 de Agosto de 1506, pelos muitos serviços prestados ao EI Rei D. Manoel I, revelam a falta de interesse em povoar, explorar, tampouco desenvolver alguma atividade. Muito mais interessados pela política que os envolvia em Portugal, a Ilha que em 1737 começava a ser reconhecidamente chamada pelo nome de seu proprietário, ficou a mercê de outros povos e nações.

\section{Período das Invasões:}

Confirmada a posse da ilha de São João da Quaresma a Fernão de Loronha, aquela ficava a mercê das demais nações em ocupá-la. E, diga-se de passagem, pela força: invasão. Em 1556 fora abordada pelos franceses não conseguindo efetivar a posse. Em 1626 foi a vez dos holandeses investirem na ocupação da ilha obtendo sucesso três anos mais tarde (1629), devida a elevada importância estratégica que a ilha possuía a rota comercial entre o Brasil e a Europa.

Boogart no livro Viver e Morrer no Brasil Holandês revela que durante os anos de 1620 diferentes naus da Companhia das Índias Ocidentais fizeram paradas regulares na ilha: Piet Heyn 14 a 23 de junho de 1625; Thomas Sickesz 26 de junho a 30 de julho e novembro de 1626; Dirck Symonsz 8 a 25 de junho de 1627, seguido por Piet Heyn em agosto. (Boogart 2005: 20).

Após a ocupação da cidade do Recife, em fevereiro de 1630, o Conselho Político que gerenciava a nova possessão holandesa, decidia povoar a llha de Fernando de Noronha. O motivo: seria a vinda de 280 negros de origem angolana que foram capturados e trazidos ao Recife por Dirck Symonsdaz (BOOGART: 2005 pp 22). A passagem desses estrangeiros pela ilha de

\footnotetext{
11 Informação encontrada no Dicionário Histórico de Portugal, de autoria de Joel Serrão. pp. 164-165. 1975 e em um documento de Francisco Botelho que alem de requerer carta sobre os limites das terras que haviam sido lavradas, bombardeiros e materiais para as obras, informava a D. João III que D. Fernando de Noronha acabara o tempo de serviço no novo mundo "com boa satisfação e se fizera digno de toda a mercê". Arquivo do Tombo, Portugal. 154007-09. Corpo Cronológico, Parte I, mç. 67, n. ${ }^{0} 120$.
} 
Fernando de Noronha esta ligada a utilização de Noronha enquanto quarentenário de gente: um celeiro humano que servia como laboratório para curar doenças.

Armazéns, oficinas, construções para moradia além do Fortim Seeburgh $^{12}$, provavelmente construído onde hoje é a Fortaleza dos Remédios. O termino dessa presença se fez quando em 26 de janeiro de 1654, foi assinada a capitulação neerlandesa no Brasil (ou Capitulação do Campo do Taborda), cujos termos fixados determinava aos membros do Conselho Supremo do Recife a entrega da cidade Maurícia, Recife, e mais forças, fortes e lugares ocupados ao Mestre de Campo e governando da Capitania de Pernambuco, General Francisco Barreto de Menezes. Recordar a ocupação holandesa na ilha de fernando é revisitar parte da chegada e presença do escravo africano no Brasil, que para a maioria dos homens, escravos e/ou livres, desembarcados na ilha "a vida apenas se diferenciava da morte". ${ }^{13}$

O que se observa é que o período de ocupação holandesa na ilha de Fernando de Noronha não motivara Portugal a cuidar "daquele porto sendo o mais importante para segurança do Brasil daquele lado". ${ }^{14}$

Preocupados com as questões na Região Platina ${ }^{15}$, que durou de 1735 a 1749, os dirigentes portugueses acabavam por deixar a ilha de Fernando de Noronha novamente a mercê de outras nações. (AULER 1946: pp 37). Foi o que aconteceu em 1736 com os franceses da Cia francesa das Índias Orientais. Ao tentar assegurar a posse da ilha, levantaram quatro barracas, que segundo Pereira da Costa, eram de elegante construção para habitação, com suas dependências, hortas, plantação de feijão, pimentas, inhames, tabacos e muitas outras do Brasil e da Europa. Ainda de acordo com Pereira da Costa, apenas ao saber da noticias da ocupação francesa é que o vice-rei do Brasil, André de Melo e Castro, Conde das Galveas, despertou a preocupação com o assunto e enviara a ilha um emissário para que esse colhesse informação a

\footnotetext{
12 De acordo com a informação obtida em BOOGART: pg 24, não há registros materiais deste fortim. Quando Portugal retoma a organização da ilha trata em erguer os pontos de defesa em cima das construção do período neerlandês e isto vale, também, para as hortas e jardins que não parece ter sido aproveitada por estes últimos.

13 Boogart PP 39.

14 Como apontava em 1798, Dom Rodrigo de Souza Coutinho, Primeiro Conde de Linhares e ministro Portugues. APEJE-PE; Arquivos Permanentes; DA; volume 14; fl. 52. Palácio de Queluz, em 18 de abril de 1798.

15 Sobre os limites territoriais entre Portugal e Espanha a formação das colônias no sul do Brasil, localizadas na região Rio da Prata, especificamente a colônia de sacramento.
} 
respeito destes estrangeiros. Diante de um relatório elaborado por este emissário, o qual não se tem registro da sua referencia ${ }^{16}$, ficava sabendo que na ilha havia doze franceses, com um cirurgião e que não havia obra alguma de fortificação, existindo, porem alguns materiais preparados de obra de construção. (Costa 1887: pp 24). Por outro lado, Auler (1946) destaca que este cirurgião encontrava estabelecido com uma construção de emergência e que estes franceses tinham perspectivas de colonização eficientes, abastecidos semestralmente da Franç. (AULER 1946: pp 37)

Diante dessas informações colhidas, o governador de Pernambuco já empossado, Henrique Luiz Pereira Freire decidiu por Carta Régia de 26 de maio de 1737 desalojar os franceses, que se encontravam em numero diminuto, e ocupar a llha definitivamente. A expedição encarregada de tal missão contava com cinco companhias de infantaria, com 250 Praças originários da província pernambucana sob o comando do tenente coronel João Lobo de Lacerda, que iniciava as obras de alojamento para as tropas e fortificações. A partir de então, ergueu-se algumas fortificações para defesa da ilha, mantendo um destacamento capaz de resistir invasões, "enquanto não se resolvia o modo porque devia ser povoada e fortificada mais regularmente". (Costa 1887: 25).

A passagem dos franceses na ilha foi fator determinante para que Portugal decidisse ocupar de fato aquele espaço insular. Primeiro, por sua característica de ancoradouro e estuário natural e por uma rica biodiversidade ecológica, que oferecia aos navegadores que transitavam em sua rota, importante apoio para a sobrevivência e, segundo, por ter representado um ponto estratégico para os navios estrangeiros, com sua característica de porto natural a ancoragem, para a invasão das terras recém conquistadas pelos portugueses: a Terra de Santa Cruz. A investida francesa foi, de certa forma, um descuido, principalmente da capitania pernambucana, já que detinha de sua posse desde os anos de 1700. Na Carta Régia expedida por D. Pedro II, ficava determinada, a Capitania de Pernambuco, manter "destacamento para a

\footnotetext{
16 Nas fontes secundarias e impressas não consta do nome do emissário encarregado de coletar as informações a respeito desses franceses. $O$ que mostra ainda como mistério a presença destes estrangeiros na passagem humana pela ilha de Fernando.
} 
sua guarnição e dois capelães que ali deveriam sempre haver". Fato não acontecido até os anos de 1737.

\section{A llha sob a Posse de Pernambuco:} as orientações de envio dos degredados sucedem-se conforme a evolução do processo de povoamento do espaço atlântico. ${ }^{17}$

Nos finais do ano de 1737, o povoamento português na ilha de Fernão começava a acontecer de fato. Após a expedição enviada contra os franceses, Lobo de Lacerda recebia ordens para erguer três fortes, "fazendo montar neles vinte e oito peças de artilharia, pondo-as em estado de poderem laborar e defender qualquer desembarque dos inimigos". (AULER 1946: pp 38)

Em 1738, três fortificações já faziam parte da defesa da ilha: Forte de Santo Antonio, Nossa Senhora dos Remédios e Nossa Senhora da Conceição, cuja responsabilidade era do engenheiro Diogo da Silveira. (AULER 1946: pp 39). Contudo, foi para o fim de cárcere que a ilha de Fernando de Noronha se destacou na historia do Brasil. Criada uma colônia correcional, que durou 201 anos, foi sendo construído o dia-a-dia do que chamamos de llha-Presídio: armazéns, sistema defensivo, vilas, etc. tudo para proteger e subsidiar a rota comercial que havia entre a colônia e a metrópole portuguesa.

Construíram a Vila de Nossa Senhora dos Remédios, com a primeira igreja, uma praça em declive e que compunha com o Forte dos Remédios a estrutura inicial ao povoamento da ilha. Em 1755, foi determinado que os cofres imperiais tivessem que contribuir com a quantia de 4:000\$000 anuais para as despesas do presídio. E, neste mesmo período, Fernando de Noronha já detinha de uma infra-estrutura de cinco fortificações regulares (Forte de Nossa Senhora dos Remédios, Forte de Santo Antonio, Forte de Nossa Senhora da Conceição, Forte de São João Batista dos Dois Irmãos e Forte de São Joaquim do Sueste), com 54 canhões, uma guarnição composta por 213 praças, entre eles, 19 oficiais, 144 soldados, 20 artilheiros e 30 índios, e seis empregados 17 VIEIRA. 2000. pp 16. Disponível em http://www.madeira-edu.pt/Portals/31/CEHA/bdigital/brasil-av.pdf. Data da
visita: 14/10/2009. 
civis, sendo dois capelães, um almoxarife, um escrivão do almoxarifado, um cirurgião e um sangrador. (COSTA 1887: 26).

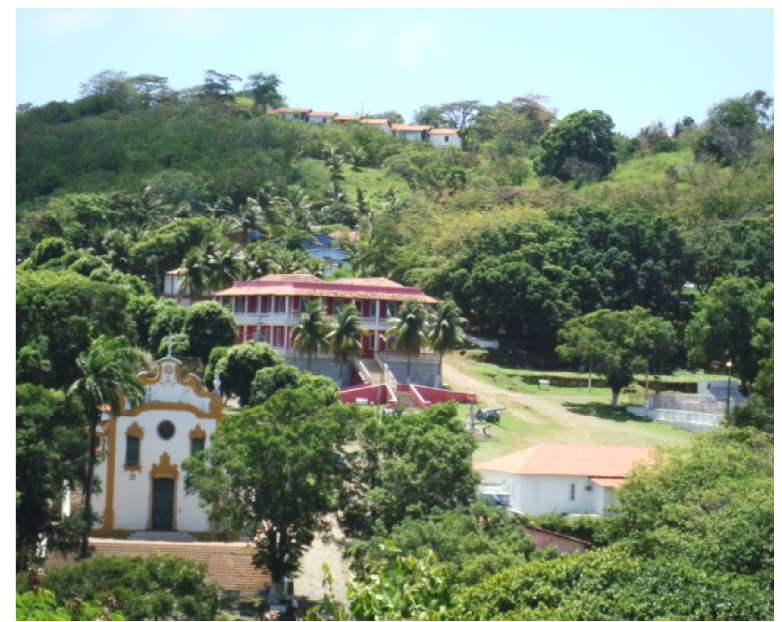

llustração 2 - Imagem projetada da Igreja dedicada a N. S. dos Remédios e do Palácio de São Miguel (prédio em cor vermelha) - antiga Sede da Diretoria do Presídio - vistos da Fortaleza N. S. dos Remédios, cujas edificações são a materialização de uma rigorosa estrategia a ocupação da llha no período das "descobertas" portuguesas. Acervo particular da autora, Janeiro de 2008.
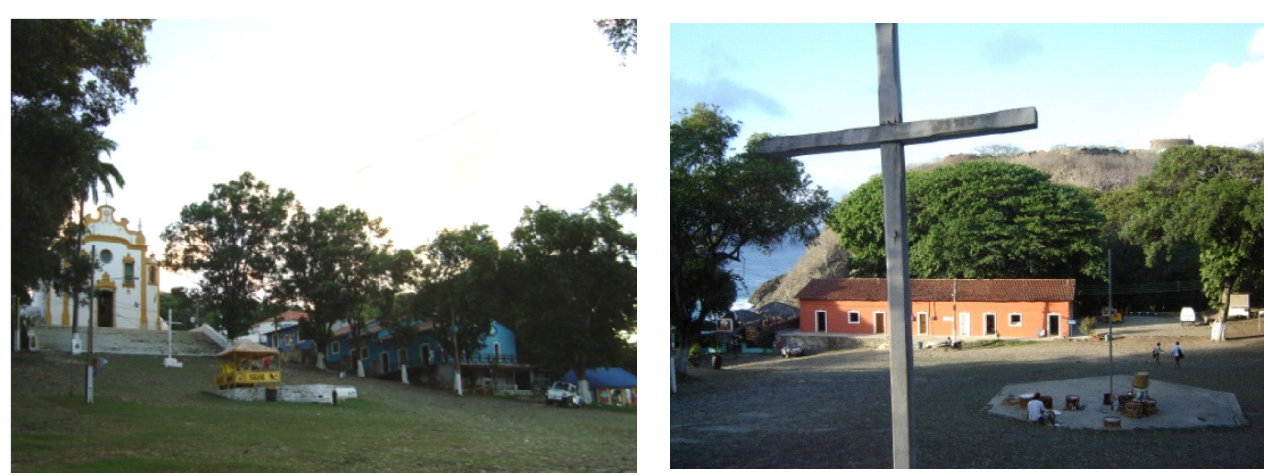

Ilustração 3 - Imagem do conjunto arquitetônico que compunha parte do projeto urbanístico do Século XVIII, como o Pátio dos Remédios (à esquerda) e o Armazém de Cereais (à direita) e que agregam a llha de Fernando de Noronha o seu caráter militar. Acervo particular da autora, Janeiro de 2008.

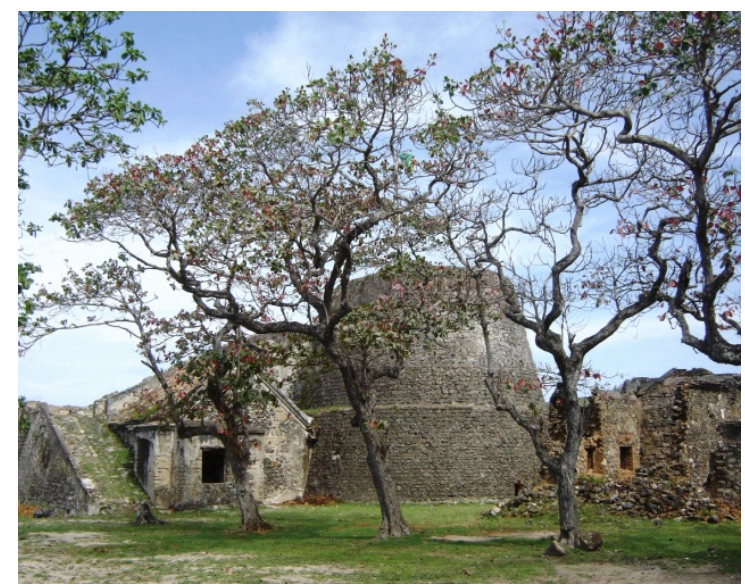

llustração 4 - Imagem interna da Fortaleza N. S. dos Remédios (1734) considerada símbolo da hegemonia portuguesa a ocupação setecentista no Brasil, em que o 
Arquipélago de Fernando de Noronha era parte dos planos para a defesa das rotas comerciais do Oceano Atlântico. Acervo particular da autora, Janeiro de 2008.

Inicialmente esta ocupação atrelava-se a promoção de uma Colônia Correcional. Esse foi o meio mais efetivo de fazer permanecer gente. Para Noronha foram mandadas várias levas de degredados, cujo intuito era promover a limpeza do tecido social para o restante do Brasil. A importância de Fernando de Noronha enquanto filtro social brasileiro, fez da teia social insular particularidades de uma historia pouco contada sobre a prisão e a violência que esta promovera.

Em 1768, sua população era em torno de 389 pessoas, constando de oficiais, praças, empregados e alguns poucos índios que eram utilizados para 0 trabalho com a agricultura. No ano de 1789, o governo português pretendeu criar na ilha uma colônia agrícola como meio de torná-la menos dispendiosa, que para Beatriz Imbiriba, "o estabelecimento da colônia agrícola fez atrasar durante séculos o desenvolvimento da ilha, tornando-a depósito de desajustados e indesejáveis de toda parte"18.

Os presos trabalhavam na construção dos fortes e casas, calçavam ruas, fabricavam cal, tecidos, farinhas e trabalhavam na pesca e na agricultura.

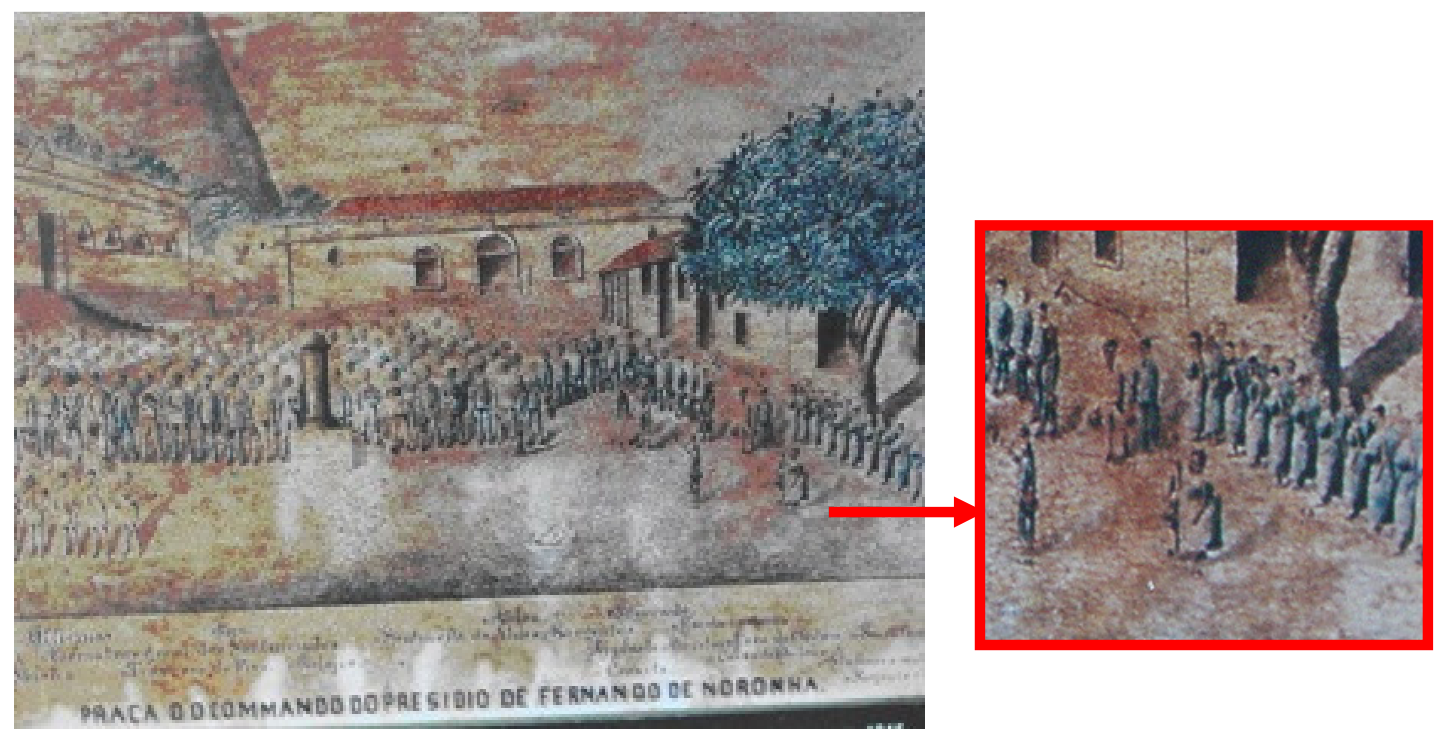

Ilustração 2 - Imagem carregada de significados sobre o cotidiano da ilha-presidio, cujas mulheres e crianças (canto dir.) socializam os espaços, juntamente com a guarda do Presidio, como se a liberdade estivesse a alcance de todos seja livre ou sentenciado.

Praça do Comando do Presídio de Fernando de Noronha, Aquarela sobre papel, Alexandre Spetz, 1845. Acervo Museu da Cidade do Recife.

18 IMBIRIBA: PP 20. 
No período da Proclamação da Independência (1822), a ilha só viera ficar sabendo da notícia mais de um ano depois. Para Pereira da Costa, era como se a ilha não pertencesse ao ordenamento patriótico brasileiro. Condição essa refletida no status de presídio, e esquecido pela sociedade continental. Proclamada a República em 1889, como primeiro ato do novo regime político os capoeiristas foram enviados a cumprirem pena em 1890.

Nos anos de 1897, Pernambuco tomou posse do presídio de Fernando de Noronha que passou a ser estadual. Isso durou até os anos de 1938, quando foi novamente entregue ao Ministério da Justiça, numa espécie de "venda", transformando-o em presídio político. Esta medida resultou na transferência dos presos correcionais para o Recife, permanecendo a Ilha somente os de caráter político.

A partir de 1942, Noronha era transformado em Território Federal. Durante a Segunda Guerra mundial, a ilha passou ao Ministério da Guerra e assim ficou sendo administrada pelas forças armadas até 1987. Foi nesse período de administração militar que a ilha recebeu grande parte da sua infraestrutura de hoje, incluindo aeroporto, estradas, escolas e o hospital.

O ano de 1988 marca o último retorno da ilha a Pernambuco. Dessa feita, na forma de Distrito Estadual. Único no Brasil. A emenda 2P00023-1 do deputado federal (PMDB-PE) Nilson Gibson conferia ao Estado de Pernambuco o direito de administrá-la conforme indicação do governador eleito. Não constando aos habitantes da ilha o direito de representação nem 0 de eleger quem o administra, sendo este cargo determinado pelo governador.

Fernando de Noronha encontra-se localizada a $545 \mathrm{~km}$ de Recife, $360 \mathrm{~km}$ de Natal e $2600 \mathrm{~km}$ da costa africana. Tem a influência do vento de sotavento e barlavento, caracterizando o mar de fora e o mar de dentro, respectivamente. Possuí uma extensão de $26 \mathrm{~km}^{2}$ de arquipélago e um clima quente de temperatura anual de $27^{\circ}$. A sua História é um misto de inferno e paraíso, sendo adjetivada por alguns comandantes pernambucanos como um "depósito de desvairados" ${ }^{\text {"19 }}$ ou "asilo de pessoas" ${ }^{\text {, }}$, como é encontrado em documentos

\footnotetext{
${ }^{19}$ APEJE; FN; 02; Fls. 352 - 353vs; ofício do Governador de Fernando de Noronha, Francisco José Martins, para o Vice-presidente da Província de Pernambuco, Francisco de Paula Cavalcante de Albuquerque. Fernando de Noronha, 18 de agosto de 1838.
} 
produzido no século XIX. Essa idéia de fazer da llha um lugar seguro "que serve de correção aos facinorosos" ${ }^{21}$, fazia dela um lugar de reclusão aos que para lá eram enviados com o objetivo de serem esquecidos pelos continentais, e daí criar um frio penitenciário, em que a prisão era a ilusória válvula de segurança da sociedade. ${ }^{22}$

\section{A Ilha Prisão:}

No dia 19 de outubro de 1837, desembarcava na ilha de Fernando de Noronha mais um comandante (tenente coronel Francisco José Soares) cuja missão seria com a guarda da rota do Atlântico, bem como a segurança não apenas da ilha, mas também de centenas de sentenciados que se viam cercado pelo muro de águas salgadas ao entorno da ilha de Fernando de Noronha, que desde a sua posse encontrava-se "em completo sossego e harmonia". 23

As pessoas que chegavam a Noronha se distinguiam entre presos comuns, políticos e militares; um corpo militar a serviço do Império; uma população residente, considerada livre; e os acompanhantes dos sentenciados, só concedidos aos ditos de "bom comportamento". No entanto, o que podemos observar nos documentos é que direta ou indiretamente, todos que para lá se destinavam, engendravam alguma punição. As pessoas que requeriam ir a ilha para acompanhar o seu ente sentenciado, talvez se sujeitava à vida insular como uma forma de sobrevivência, já que, mesmo com o "degredo forçado", Ihe era garantido moradia e vencimentos. Talvez por meio de conseguir promoção mais rápida na hierarquia militar, os que estavam a serviço do gestor da ordem brasileira acabavam também sentindo o peso de estar ilhado.

\footnotetext{
20 APEJE; FN; 4C; 1852.

21 Idem.

22 PIERROT: pp 266.

${ }^{23}$ APEJE; Arquivo Permanente, FN 02; fls.223 - 227. Ofício do governador de Fernando de Noronha, Tenente Coronel Francisco José Martins. Fernando de Noronha, 19 de outubro de 1837.
} 

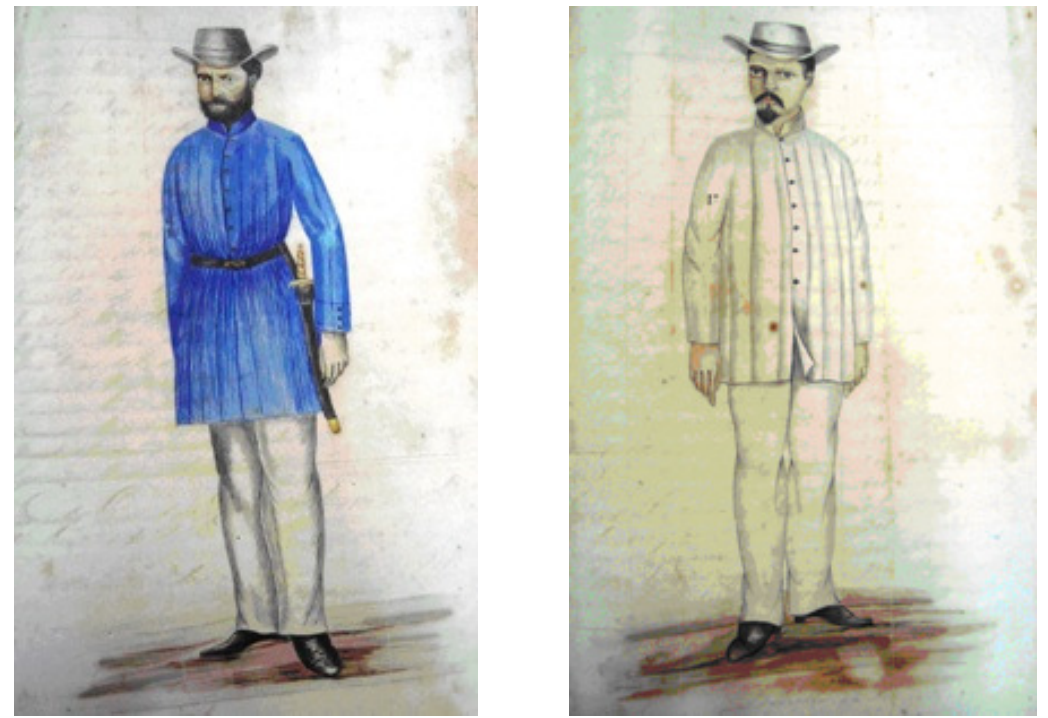

Ilustração 3 - Imagens reproduzidas pelo escrivão do Comandante do destacamento de Fernando de Noronha Capitolino Cezar Loureiro, em 16 de Maio de 1885, relatando a necessidade em melhorar as condições de vestimentas tanto de sentenciados como da guarda. APEJE-PE; Arquivo Permante; Série FN; 24, ano 1885, Fls. 266 e 267.

Esse sabor um tanto que "amargo" da vida insular no presídio é visto na documentação quando requerimentos são enviados, questionando 0 isolamento em que viviam os que cumpriam o real serviço. Posto que "não somente serve de correção aos fascinorosos, como que é a chave do norte do Brasil e um seguro depósito para os desvairados."24

A divisão social, na esfera do presídio, pode ser observada em mapas enviados anualmente ao governo da província, como um instrumento de controle social e ordenamento militar. A sociedade da ilha-presídio tem como característica quatro pilares: esquecimento, isolamento, transgressão e disciplina, dirigida pelo comandante, tido como o representante do governador de Pernambuco. Dividia-se entre oficiais e empregados, praças de Pret, anistiados, pessoas livres residentes não contempladas nas famílias, sentenciados(as) e presos(as), todos seguindo as ordens e a disciplina do presídio, independente da sua condição social.

Se pegarmos um espaço cronológico de 20 anos (1830 - 1850) observaremos que a população insular, seja militar, seja carcerária, tem uma diminuição em 5,96 \%. A incidência feminina será vista em 4,80 \% entre as idades de 1 a 60 anos. Sendo estas distribuídas entre sentenciadas, escravas

\footnotetext{
${ }^{24}$ APEJE; Arquivo Permanente, FN 02; fls 352 - 353vs; Ofício do governador de Fernando de Noronha, Tenente Coronel Francisco José Martins. Fernando de Noronha, 18 de agosto de 1838.
} 
e acompanhantes de presos e militares. Os oficiais e empregados têm uma baixa de $25 \%$. Saem de 86 , em 1849, para 64 , em 1852. Os sentenciados, entre masculinos e femininos caem em 12,64\%, somam 348, em 1849, e 392 , em 1852. Os praças de Pret de 111, em 1849, para 100, em 1852, num decréscimo de 9,99\%. E as pessoas livres residentes de 89 para 65, 26,96\%, nos anos citados. ${ }^{25}$

Pensar cotidiano carcerário em Noronha é levantar questionamentos acerca do tipo de cárcere ao qual estavam expostos os que para lá iam, seja a serviço do Estado, seja por cumprimento de uma sentença. O que se define como prisão e presídio dentro do século XIX é visto com um direcionamento diferente em Noronha.

Os ofícios produzidos pelo comando da ilha, durante o século XIX, trazem atitudes flexíveis quanto à vida no degredo em Noronha. Concessões para os presos, como a presença da família, abono da pena por bom comportamento, são vistos nos ofícios produzidos. Talvez por estratégica para diminuir as tensões na vida do cárcere, haja vista que o próprio efetivo militar se demonstrava insignificante frente ao contingente de presos, "+/- 400 pessoas entre deportados e sentenciados, fora moradores vigiados por 40 e tantos soldados"26. O comandante Francisco José Martins "convencido da impossibilidade de ser reforçado o destacamento do presídio", mantém "a paz da ilha com os fracos recursos que possui". Diz ao presidente da província de Pernambuco, Vicente Thomaz Pires de Figueiredo Camargo, que "fique descansado que irá empregar os melhores esforços para que o sossego não seja alterado"27.

Portanto, pensar presídio na ilha de Fernando de Noronha desconstrói a própria imagem que temos do presídio feito por concreto, cercado por arames farpados e um rigor na segurança e vigiamento, aos quais fomos (e somos) acostumados a produzir, tanto no concreto quanto no imaginário.

A vida no cárcere, em Noronha, era de uma violência psicológica tal, que não se fazia necessário torná-la real, posto que o limite era o oceano e os seus

25 As fontes utilizadas para o levantamento estatístico foram retiradas do APEJE; volume 4, fl.112 e 4C, fl.106.Datados: 30 de agosto de 1849 e $1^{\circ}$ de julho de 1852, respectivamente.

${ }^{26}$ APEJE; Arquivos Permanentes, FN 02; fls 387 - 390. Ofício do governador de Fernando de Noronha, Tenente Coronel Francisco José Martins. Fernando de Noronha, 19 de fevereiro de 1839.

${ }^{27}$ APEJE; Arquivos Permanentes, FN 02; fls.348 - 349. Ofício do governador de Fernando de Noronha, Tenente Coronel Francisco José Martins. Fernando de Noronha, 14 de agosto de 1838. 
muros era o mar, ressiginificado com as águas transparentes que o mar que circunda Noronha nos proporciona, repleto de significados. Essa transparência faz com que o cotidiano de Noronha se torne algo visível. E de visibilidades precisava a ilha ser construída para que o vigiar fosse executado, cujos comandantes pudessem ter o controle efetivo de todo o espaço insular, transparecer dos seus olhos uma idéia de vigília e ordenamento.

Esse muro também representava o carceramento psicológico que os sentenciados de Fernando de Noronha sofriam, com efeitos tão semelhantes ao de um paredão concretamente construído para que representasse os limites prisionais. A psique influenciava nesse sentido, em que o limite para tal estava condicionado no mar. Quem se atrevia a transpô-lo? Quem enveredaria o transparente das águas fernandinas? Os corajosos não voltaram: "distante daqui légua e meia foram vistos ainda pela guarnição até o pôr do $\mathrm{sol}^{28}$. Acabaram sendo sugados pelo paredão de águas salgadas. Talvez o encantamento da Alamoa fez com que esses se dispersassem do concreto panóptipo insular e preferiram não voltar a 'ilha maldita', "deserta e triste, onde mora a dor e o sofrimento, que macula e desespera, para onde a justiça pernambucana degreda a escória social”29.

Tomada como castigo, a idéia prisional em Fernando de Noronha girava na ordem de serviços e manutenção dos edifícios. Eram tidos como um aparato para que a ilha se ordenasse O "esquecimento" produzido pelos ditos continentais substituía as paredes de concreto que simbolizava o carceramento dos considerados personas non gratas para a sociedade da época. Esse esquecimento fazia-se sentir a necessidade em alertar, sempre que possível, ao governo pernambucano a necessidade de cuidar desse pedaço de Brasil no atlântico. A todo tempo os comandantes da llha enviavam ofícios, cartas e requerimentos os quais o assunto central era esse dito esquecimento.

O que chamo de ilha-presídio era imaginada como a própria parede do confinamento e nisso podemos também englobar os que estavam a serviço da ordem, como já havia dito anteriormente.

\footnotetext{
${ }^{28}$ APEJE; Arquivos Permanentes, FN 4B, fl. 101vs Ofício do Coronel Comandante José Maria Ildefonso Jérome da Veiga Pessoa. 18 de Agosto de 1851.

${ }^{29}$ AMORIM NETO. Fernando de Noronha - 2a edição. Editora a noite, Rio de Janeiro: 1946.
} 
Dentro desse ambiente penitenciário, também se observa o que definimos como o "cárcere do cárcere". Havia, na verdade, uma punição dentro do cárcere aos que não cumprissem com a disciplina e a ordem estabelecidas pelo gestor da llha. A esse dito "cárcere do cárcere", presos como Antônio Borges da Fonseca líder da revolução Praieira (1834 - 1848) e Francisco Pedro Vinagre líder da revolução do Pará de 1834, foram submetidos, sejam por ameaçar a dita "Paz no Presídio"30, sejam por não poderem fazer repercutir as suas idéias contra governo. Esses presos políticos eram enviados a llha Rata como maneira de afastá-los dos demais. "A Ilha dos Ratos"31 servia como uma espécie de "quarentena disciplinar" até que se fosse instaurada um Conselho de investigação aos considerados subversivos ${ }^{32}$.

Essa estratégia de cárcere criada entre e dentre as relações de poder instituídas transpassava a esfera psicológica, uma vez que o isolamento era tido como fator crucial para quem se encontrava em degredo e agora estava sendo banido do convívio do restante do presídio.

O cotidiano da ilha se encontrava entre as obrigações da prisão e a ociosidade insular. A pesca, tida como sobrevivência para uns, não pode ser considerada como a atividade principal. Aos presos era destinada a confecção de sapatos e vassouras, a extração do azeite de carrapato $^{33}$, a produção de farinha de mandioca, tidas como atividades legais e que enriqueciam os cofres dos Armazéns Nacionais. No entanto, o contrabando das "bebidas espirituosas", como era chamado o aguardente, fez com que o comando da ilha, articulasse a sua legalidade, percebendo que deste comércio creditaria os cofres do Império.

A idéia de carceramento/reclusão, em Noronha se diferenciava da divisão de espaços entre "presos" e "livres" que existia no continente. É perigoso afirmar que em Noronha havia uma divisão de espaços entre os que pertenciam ao 'cárcere-punição' e aos que pertenciam à 'ordem-moral' da

\footnotetext{
30APEJE; Arquivo Permanente, FN 02; fls 249 - 250. Ofício do governador de Fernando de Noronha, Tenente Coronel Francisco José Martins. Fernando de Noronha, 12 de janeiro de 1838.

31 Possuía este nome, devido a população de ratos, trazidos pelas embarcações que atracavam no porto da llha, ser significativamente grande. Nesta parte da ilha, os presos considerados subversivos eram enviados para viverem um regime de esquecimento, do próprio convívio dos que residiam na ilha principal.

${ }^{32}$ APEJE; Arquivo Permanente, FN 02; fls.423 - 431; Ofício do governador de Fernando de Noronha, Tenente Coronel Francisco José Martins. Fernando de Noronha, 03 de dezembro de 1839.

33 APEJE; Arquivo Permanente, FN 02; fls.382/382vs; Ofício do governador de Fernando de Noronha, tenente coronel Francisco José Martins. 27 de dezembro de 1838.
} 
sociedade. Todos conviviam no mesmo ambiente. Afinal, o que foi defendido anteriormente, é que direta ou indiretamente, todos estavam reclusos ao esquecimento, ao isolamento. E são essas duas palavras que são vistas o tempo todo nos escritos dos comandantes.

O grupo social que antes vivia imerso sobre a moral e o bom costume social - e ai me refiro aos que serviam ao Estado, aos civis residentes e seus respectivos acompanhantes (famílias) - acabavam por sentir o amargor do cárcere. Em um mesmo espaço "culpados e inocentes" sentiam o peso do esquecimento. Esses espaços comuns só serão diferentes quando nos referimos às residências concebidas a cada um. Sentenciados nas "casas de sentenciados"; oficiais, nos quartéis; civis nas suas residências e assim por diante. Ademais os espaços ditos comuns quebravam com uma divisão social sentida no continente. Contudo não sejamos inocentes em afirmar que não havia uma divisão social. Essa divisão era vista de uma forma diferente da tida na sociedade brasileira continental. Talvez por ser o militarismo a força social dentro da ilha, a estrutura social será a disciplina dos quartéis.

Dentro desses espaços ditos comuns se encontravam a Escola de Primeiras Letras. Nesse ambiente, filhos de oficiais, de sentenciados e de civis compartilhavam o aprendizado. Às vezes a escolha do mestre era decorrente de uma punição, outra por simples mérito da leitura. O sentenciado político Daniel Rodrigues de Santana foi agraciado para essa função. Considerado um grande educador dedicou-se a educação dos filhos de oficiais, de presos e de civis. Daniel Rodrigues era um desterrado perpétuo era "assíduo e caprichoso em fazer que os alunos tirassem proveito, o que em verdade tem sido obtido"34.

Também se achavam enquanto espaços comuns os Armazéns Nacionais; ao comércio dos vivandeiros ${ }^{35}$; aos cargos de praças, ocupados também por sentenciados ${ }^{36}$; enfim, ao que se relaciona de espaços públicos, já que o privado era destinado a cada grupo específico. ${ }^{37}$

\footnotetext{
34 APEJE; Arquivo Permanente, FN 4B; fl. 49, Fernando de Noronha, 07 de abril de 1851.

35 Pessoas responsáveis pelo comércio praticado por particulares, os quais recebiam concessões do governo pernambucano para tal fim.

${ }_{36}$ Cargos ocupados por aqueles presos ditos de bom comportamento, como uma maneira de sanar o baixo contingente militar.

37 Não podemos deixar de lembrar que a divisão do que é publico e privado em Noronha se diferenciava do continente, por serem lugares comuns entre "presos" e "livres". O que não acontecia no continente, onde o preso estava trancado na própria prisão, tirando-o do convívio dos ditos "livres".
} 
A idéia de prisão em Noronha era a do esquecimento. A ilha era depositária de tudo o que lembrasse desordem, imoralidade, distúrbios. Tentava-se transferir para a llha a responsabilidade de ser um filtro social capaz de executar uma limpeza. A tensão era uma constante. Por mais flexibilidade que os comandantes tinham para tornar o ambiente carcerário 0 mais "tranqüilo", a intenção de sublevação e fuga estavam presentes. Sempre que fosse possível, fugir era um desejo pertinente a todos. Direta ou indiretamente, todos, "livres" e "presos", pensavam em sair do esquecimento.

Paraíso para alguns na atualidade, o estigma de prisão vem desde 1739, quando se cria a imagem de um lugar "misterioso de horror"38, cujo silencio é marcadamente forte em uma história sobre o viver ilhado, cercado por dores e expiação.

A llha Prisão pode ser entendida como o esquecimento e o silêncio de um ambiente que servia a ordem, sejam os personagens "livres" ou "presos". Uma história repleta de vozes.

REFERÊNCIAS BIBLIOGRÁFICAS:

1. AMORIM NETO. Fernando de Noronha - $2^{\mathrm{a}}$ edição. Editora a noite, Rio de Janeiro: 1946.

2. ARAGÃO, Campos de. Guardando céu nos trópicos: ilha de Fernando de Noronha. Editora Biblioteca do Exército. Rio de Janeiro: 1950.

3. Arquivo Público Estadual Jordão Emerenciano - PE, Arquivos permanentes.

4. AULER, Guilherme. Os Fortes de Fernando de Noronha. In: Revista do Arquivo Público de Pernambuco, Recife, v.1, n.2, 1946.

5. BURKE, Peter. A Escrita da História: novas perspectivas /Peter Burke (org.); tradução de Magda Lopes. - São Paulo: Editora da Universidade Estadual Paulista, 1992. - (Biblioteca básica).

6. CANDIOTTO, César. Foucault: uma história Crítica da verdade. Trans/Form/Ação: Revista de Filosofia, Unesp - Marília (SP), v. 29, n. 02, p. 65-78, 2006. Disponível em: http://www.scielo.br/scielo.php. Acesso em 02 de abril 2010.

7. COSTA, Pereira da. A ilha de Fernando de Noronha: notícia histórica, geográfica e econômica. Pernambuco, 1887.

8. DIEGUES, Antonio Carlos. Ilhas e mares: simbolismo e imaginário. São Paulo: Editora HUCITEC, 1998.

9. HULSMAN, Lodewijk; TEENSMA, B. N.; BOOGAART, Ernst Van Den; MENEZES, Jose Luiz Mota; SCHALKWIJK, Frans Leonard. Viver $E$

\footnotetext{
${ }^{38}$ ARAGÃO: pp 27.
} 
Morrer No Brasil Holandes. Org: Marcos Galindo. Recife: Fundaj. Ed. Massangana, 2007.

10. IMBIRIBA, Beatriz de Lalor. História de Fernando de Noronha. Imprensa Industrial. Recife, 1951.

11. PIERROT, Michelle. Os excluídos da História: operários mulheres e prisioneiros. Tradução Denise Bottman. - $3^{\underline{a}}$ edição. Rio de Janeiro: Paz e Terra, 2001.

12. Plano de manejo da área de preservação ambiental de Fernando de Noronha, atol das Rocas e São Pedro e São Paulo, junho de 2005.

13. SERRÃO, Joel. Dicionário Histórico de Portugal. Vol. III, pág. 164-165, Porto, 1975.

14. VIANNA, Hélio. História do Brasil. Editores melhoramentos, 1961.

15. VIEIRA, Alberto. As ilhas, as rotas oceânicas, os descobrimentos e $o$ Brasil. Funchal-Centro de Estudos de História do Atlântico. Madeira (Portugal): Biblioteca Digital, 2000. Disponível em http://www.madeiraedu.pt/Portals/31/CEHA/bdigital/brasil-av.pdf. Acesso em 14 de outubro de 2009. 